\title{
Modelling the effect of artificial lighting on plant growth
}

\author{
S.Yu. Efremova ${ }^{1}$, E.G. Kulikova ${ }^{2}$, V.V. Konovalov ${ }^{3}$, and E.I. Tikhomirova ${ }^{4}$ \\ ${ }^{1}$ Penza state technological University, Baidukova street /Gagarin street, 1A / 11, Penza, 440039, Russia \\ ${ }^{2}$ Penza state agrarian University, 30 Botany street, 440014, Penza, 440014, Russia \\ ${ }^{3}$ Penza state technological University, Baidukova str/Gagarin street, 1A / 11, Penza, 440039, Russia \\ ${ }^{4}$ Saratov state technical University named after Yuri Gagarin, 77 Politechnicheskaya street, Saratov, 410054, Russia
}

\begin{abstract}
The organisation of even minor additional lighting on the General light background gives a noticeable effect and is the primary task of vegetable growing. The influence of different peaks of 440-450 $\mathrm{nm}$ and $650-660 \mathrm{~nm}$ of the spectrum for optimal plant growth was experimentally studied. The lack of functional mathematical models for describing the development of plants indicates the need for scientific justification of the optimal spectral composition of the photosynthetically active zone on the example of a specific culture of protected soil. The dynamics of plant height growth in various lighting options is compared: without additional artificial lighting, when using a DNAT lamp, a GLP-FH-56-B lamp, a GLPFH-56-R lamp, a GLP-FH-56-RB lamp. The obtained functional models of growth in the first two months of vegetation with a different spectrum of additional lighting with good correlation describe power equations.
\end{abstract}

\section{Introduction}

To obtain a strong and healthy planting material, the duration of daylight for plants should be at least $10 \ldots 14$ hours. An increase in the rate of photosynthesis occurs at lower light levels, when the leaf area is small, than with the developed leaf apparatus of adult plants. Therefore, on a General weak light background, even minor additional lighting-additional illumination of seedlingsgives a noticeable effect, and the primary task of vegetable growing is to organize additional lighting. This was also noted by Canadian researchers [1]. In this regard, it is interesting to study the spectral composition of light that is most effective for growing plants [2]. Detailed scientific research on the influence of different spectra for optimal plant growth on specific plant species has also been carried out by many foreign scientists. The influence of the type of light source on tomatoes in terms of photosynthetic activity is diverse and multi-directional [3]. The effectiveness of the influence of blue LEDs on the photosynthetic activity of tomato plants was noted [4] where it was shown that the combination of blue wavelengths improves the amount of chlorophyll pigment. In [5], it was noted that the influence of blue light was useful for cucumber, but not for tomatoes. The authors ' research $[6,7,8]$ discusses the specific response of plants to different wavelengths. There was a clear reaction of tomato plants before 3 weeks of growing under a redder and darker red light [2].

It is reasonable to scientifically substantiate the optimal spectral composition of the photosynthetically active radiation zone [9.10] for a specific crop of protected soil $[5,6,7,8]$, and in this regard, we have studied the influence of peaks of 440-450 nm and 650$660 \mathrm{~nm}$ of the spectrum of experimental led lamps on the phases of tomato development.

The analysis of these works and the works of other authors indicates the absence of functional mathematical models of plant development. Therefore, the purpose of this work is to identify the functional model of changes in the height of tomato plants during their growth under the light influence of various light sources.

\section{Results of experimental research and modelling methods}

The numerical simulation of growth is based on the results of experimental studies of additional lighting of tomato plants with various lamps during the first two months of vegetation.

The tomato goes through several stages in its development. One of the main indicators that characterize the development of plants in the initial phases, of course, is the height of plants. Under the DNAT control lamp, the plants immediately began to stretch and showed clear signs of light starvation. In the phase 3-4 of these sheets, this trend increased, and the plants under the control lamps stretched and clearly lagged in development.

In the phase of formation of the first ovary, the dynamics remained, and plants under the test lamps with peaks in the blue and red zone reacted most sensitively to these types of lighting, which is confirmed by the results of biometric studies (Fig. 1). 


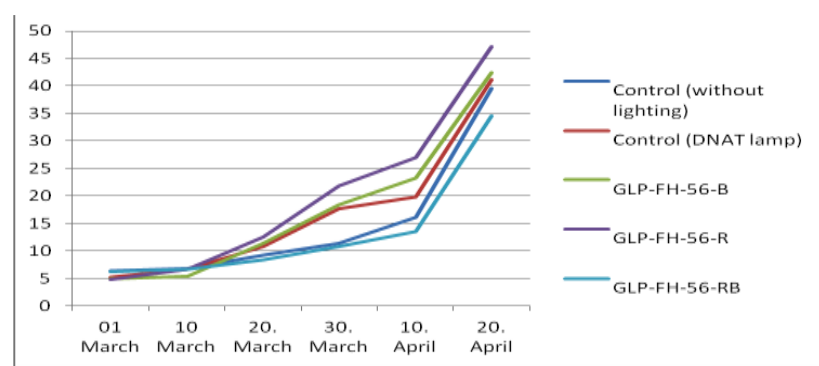

Fig. 1. Dynamics of height of tomato plants under the studied lamps, cm.

During the flowering phase, there was already a clear advantage of the light exposure of the tested lamps over the DNAT lamp. In addition, the onset of this phase was noted ten days earlier under the lamp with a peak in the blue zone and 7 days - in the red, compared to the control lamp. The plants formed the largest land mass, had good foliage, bright leaf colour and powerful inflorescences.

The study of the dynamics of plant growth under the studied lamps showed (Fig. 1) that the GLP-FH-56-R lamp with a peak in the red zone - had the greatest effect on linear growth rates on tomato plants. The daily increase is $15.3 \%$, compared to the irradiated control lamp.

The modelling method provided for processing the results of experimental studies on the average values of plant height at the time of measurement. To process the obtained data, we used the capabilities of the built-in statistical processing functions of the MathCAD program to obtain regression models of various types. The power model most accurately describes the experimental data.

\section{Simulation results and their analysis}

As a result of statistical processing of experimental results (Fig. 1), using the MathCAD-14 mathematical package, a number of functional models of plant height were obtained for various lighting methods (Fig. 2): Ywithout additional lighting; Y0- DNAT lamp; Y1-GLPFH-56-B lamp; Y2-GLP-FH-56 - R lamp; Y3-GLP-FH56- $\mathrm{RB}$ lamp. The correlation coefficient $\mathrm{R}$ is given for each model.

Graphical analysis of the results (Fig. 2) and numerical values of the correlation coefficients of the models $\mathrm{R}$ allowed us to distinguish the coincidence of the trends of experimental values and the power function.

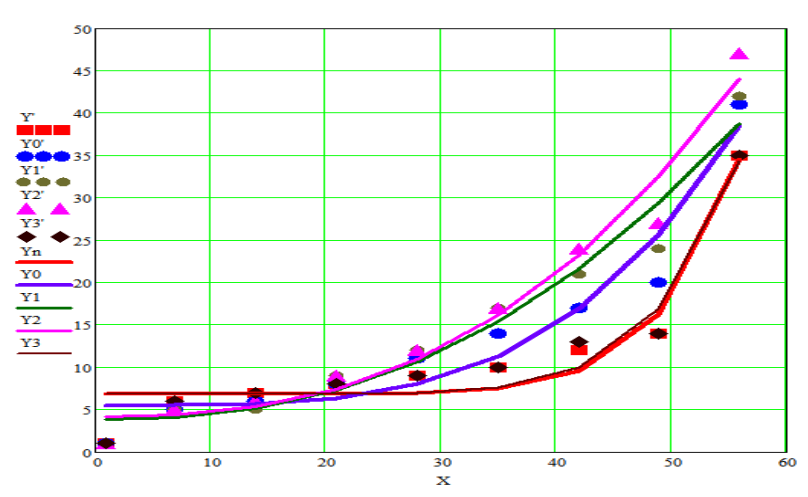

Fig. 2. Graphic results of modelling plant growth by power functions: $g$, yy - without additional lighting; Y0-DNAT lamp;Y1-GPP-NR-56-B lamp;Y2lampglp-NR-56 - p; Y3 lampglp-NR-56-RB; the presence of a "stroke" shows experimental results; the absence of a "stroke" shows the calculated values for the power model.

Power model of growth $(\mathrm{cm})$ of tomato plants:

$$
\begin{gathered}
Y=6.823+2.084 \cdot 10^{-13} \cdot X^{8.079} ; R=0.921 \\
Y_{0}=5.484+1.037 \cdot 10^{-5} \cdot X^{3.72} ; R=0.932 \\
Y_{1}=3.78+2.772 \cdot 10^{-3} \cdot X^{2.346} ; R=0.957 \\
Y_{2}=4.157+1.308 \cdot 10^{-3} \cdot X^{2.565} ; R=0.967 \\
Y_{3}=6.8+1.928 \cdot 10^{-12} \cdot X^{7.525} ; R=0.914
\end{gathered}
$$

Analysis of graphs of functional growth models shows the correspondence of power models to experimental results, which is confirmed by numerical values of correlation coefficients: $\mathrm{R}=0.914 \ldots 0.967$. Therefore, these functional models can be used to describe the growth of plants in the first two months of vegetation.

The experimental ratio of plant height values with additional lighting relative to the option of no additional lighting is determined (Fig.3.a) based on experimental data. For rice. 3.b) results of comparison of calculated data on power models are given.

Also, the analysis of graphs shows the General trends of changes in plant height with a period of plant growth of more than 2 weeks. The most intense difference in plant height is from 30 to 50 days. Later, the height of the plants is leveled, but differences remain.

The coefficient of increase in plant height for different variants of additional lighting relative to the absence of additional lighting is at the end of the experiment: $\mathrm{K}=1.17-\mathrm{DN}$ DNAT; $\mathrm{K}=1.2$-GL GLP-FH$56-\mathrm{B} ; \mathrm{K}=1.343$ - for the lamp GLP-FH-56-r; $\mathrm{k}=1$ - for the lamp GLP-FH-56-RB. 
a)

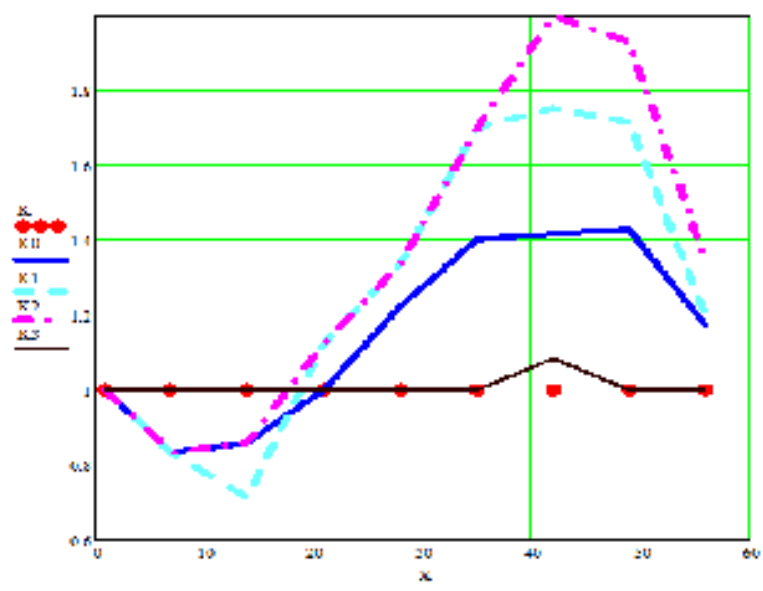

b)

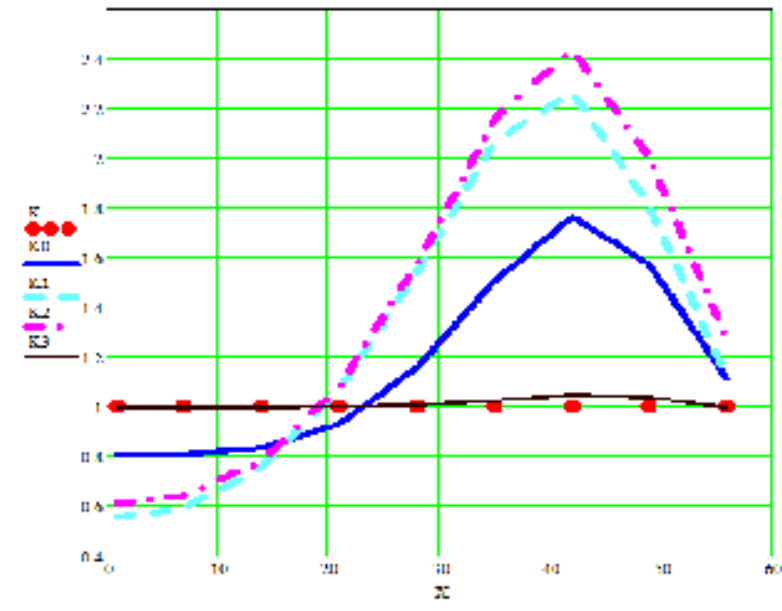

Fig. 3. The dependence of the growth duration on the growth ratio in the studied variants of additional lighting for growth in the absence of additional lighting: $\mathrm{a}$ - experimental data; $\mathrm{b}$ calculated data on models; K-without additional lighting; K0DNAT lamp; K1-GPP-NR-56-B lamp; K2-GPP-NR-56-p lamp; K3-LP-NR-56-RB lamp.

\section{Conclusion}

The most effective lighting option that affects the growth of tomato plants in the first two months of vegetation is GL GLP-FH-56-R. the most significant differences in plant height in the second month of vegetation, in the future, the differences are reduced. The increase in height in the first two months with a good correlation is described by power equations of functional models.

\section{References}

1. 1. Dorais, M., Gosselin, A. physiological response of greenhouse vegetable crops to additional lighting / / Acta Horticulturae Volume 580, 2002, P. 59-67

2. 2. Gorbachevskaya O., Vogel K., Kappis S., Schreiter H. light-red and dark-red, as well as distant red light when growing tomatoes / / fur kulturpflanzen magazine volume 68, issue 10, 2016, Pp. 295-305.

3. 3. Rakutko S., Alsina I., Avotin A., Berzina K. manifestation of the effect of fluctuating asymmetry of bilateral signs of growing tomatoes in industrial greenhouses / / technique for rural development volume 17, 2018, Pp. 186-191

4. 4. Metera, A., Wtulich, J. Gajc-Wolska, J., Bujalski, D. Kowalczyk K. estimation of parameters of development of tomato seedlings (Solanum lycopersicum) with different quality of led lighting//Acta Horticulturae Volume 1142, October 31, 2016, P. 383-388.

5. 5. Ménard, C., Dorais, M., Hovi, T., Gosselin, A. development and physiological responses of tomatoes and cucumbers to additional blue color / / Acta Horticulturae Volume 711, June 2006, P. 291296.

6. 6. Singh, D., Basu, C., Meinhardt-Wolweber, M., Roth, B. LEDs for energy-efficient greenhouse lighting/ / reviews of renewable and sustainable energy sources volume 49, September 1, 2015, pp. 139-147.

7. 7. Olle M., Virshile A. Influence of led lighting on the growth and quality of greenhouse plants / / agricultural and food science volume 22, issue 2, 2013, Pp. 223-234.

8. 8. Kulikova E. G., Efremova S. Yu. Politaeva N., Smyatskaya Yu. efficiency of alternative led system grow light / / IOP conference series: earth and environment science, 2019, 288(1), 012065.

9. 9. Vinkovic, T., Parajanovi, N., Tkalec, M., Lisak, M., Declich, T., Zmaic, K., Vidakovic, M. effect of led lighting on the yield and growth of tomatoes / / PoljoprivredaVolume 22, issue 1, 2016, P. 3-9

10. 10. Durie, A. the Influence of (additional) lighting on the production of vegetable crops/ / Acta Horticulturae Volume 418, 1 December 1997, P. 3336. 